Article

\title{
Population Dynamics of the 'Golden Tides' Seaweed, Sargassum horneri, on the Southwestern Coast of Korea: The Extent and Formation of Golden Tides
}

\author{
Sun Kyeong Choi ${ }^{1} \oplus$, Hyun-Ju Oh ${ }^{2}$, Suk-Hyun Yun ${ }^{2}$, Hyuk Je Lee ${ }^{3}$, Kyounghoon Lee ${ }^{4}(\mathbb{D}$, \\ Young Seok Han ${ }^{5}$, Sangil Kim ${ }^{2, *}$ and Sang Rul Park ${ }^{1, *(\text { D }}$ \\ 1 Estuarine \& Coastal Ecology Laboratory, Department of Marine Life Sciences, Jeju National University, \\ Jeju 63243, Korea; choisk@jejunu.ac.kr \\ 2 Ocean Climate \& Ecology Research Division, National Institute of Fisheries Science, Busan 46083, Korea; \\ hyunjuoh@korea.kr (H.-J.O.); younsh@korea.kr (S.-H.Y.) \\ 3 Molecular Ecology and Evolution Laboratory, Department of Biological Science, College of Science and \\ Engineering, Sangji University, Wonju 26339, Korea; hyukjelee@sj.ac.kr \\ 4 School of Marine Technology, College of Fisheries and Ocean Sciences, Chonnam National University, \\ Yeosu 59626, Korea; khlee71@jnu.ac.kr \\ 5 Research \& Development Center, Neo Environmental Business Co., Bucheon 14523, Korea; \\ hanulva@neoenbiz.com \\ * $\quad$ Correspondence: marine7@korea.kr (S.K.); srpark@jejunu.ac.kr (S.R.P.); Tel.: +82-64-754-3425 (S.R.P.)
}

Received: 6 March 2020; Accepted: 1 April 2020; Published: 6 April 2020

\begin{abstract}
Since 2015, troublesome masses of floating Sargassum horneri have been introduced via ocean currents and winds to the southwestern coastline of Korea, including Jeju Island. These massive mats have caused considerable damage to the aquaculture industry, tourism, and the marine ecosystem. Most previous studies of $S$. horneri have focused on cultivation, the development of gene markers, and photosynthetic activity, but few data on population dynamics are available. We investigated the population dynamics of native S. horneri off the southwestern coast of Korea with the aim of predicting the formation of golden tides. Populations at two sites had obligate annual life cycles. Thalli were recruited during the period September-November, grew during the period December-April, and senesced by July. This pattern reflected seasonal trends in water temperature. Specific growth rates and heights of the thalli at Munseom were significantly higher than those at Jindo. The greatest environmental difference between the two sites is probably the degree of exposure to wave action. Mortality density (thalli lost per unit area) in the Munseom population was highest during the period December-January (i.e., 2-3 months after recruitment) and in March. Most thalli in the Jindo population died off in July when water temperatures increased. The maximum average biomass of $S$. horneri thalli detaching from the substrata reached $1.6 \mathrm{~kg}$ fresh weight $\mathrm{m}^{-2}$ during January and March. Thus, large-scale drifting mats were formed by S. horneri detachment from the substrata. Despite the differences in space and environment between China and Korea, our findings will enable quantitative assessments of the overall floating Sargassum biomass in the East China and Yellow Seas.
\end{abstract}

Keywords: Sargassum horneri; golden tides; population dynamics; mortality; detached biomass

\section{Introduction}

Massive floating macroalgal blooms (so-called seaweed tides) of increasing frequency, magnitude, and severity have been reported from coastal regions around the world [1,2]. 'Green tides' formed by blooms of species of the genus Ulva, and 'golden tides' formed by blooms of Sargassum species 
are exemplars of seaweed tides globally. These tides have been linked to coastal eutrophication resulting from inorganic nutrient inputs [3,4]. A few recent studies have emphasized the role of high water temperature during winter (a result of global climate change) as a factor in the formation and magnitude of seaweed tides [2,5]. Floating seaweed mats provide essential habitats for a variety of fish, and they serve as hotspots for biodiversity and productivity [6-8]. However, they wash ashore along the coastline, causing serious environmental, ecological, and economic problems [1,4,9].

Golden tides (mainly Sargassum fluitans and S. natans) have occurred periodically during the summer along the coastlines of the Gulf of Mexico, with recent range extensions across the central Atlantic Ocean from the Dominican Republic to Ghana [2,10]. Large-scale drifting S. horneri mats originating off the Chinese coast have been observed regularly in the East China Sea, where the magnitude has been increasing since the first decade of this century [5,11,12]. In 2017, massive Sargassum mats were observed at the Pyropia farms in the offshore region of Jiangu Province, and they led to an economic loss of at least $\$ 70$ million in the nori industry of Dafeng in Jiangsu Province, China [12,13]. In 2015, a massive drifting mat of S. horneri released from Zhejiang Province, China, was transported by ocean currents and wind to the southwestern coasts of Korea, including Jeju Island [14]. During the period 2015-2018, hundreds of thousands of tons (wet weight) of S. horneri were observed on the southwestern coasts of Korea, including Jeju Island. The removal of about $33 \times 10^{3} \mathrm{t}$ fresh weight from beaches, ports, and aquaculture farms involved 30,000 people at an estimated cost of \#2.8 billion ( $\approx \$ 2.55$ million). This estimate did not include losses incurred by the fishing and tourism industries (unpublished data). Golden tides led to an economic loss of 0.8 billion ( $\approx \$ 0.73$ million) by seaweed aquaculture operations along the coast (unpublished data). Consequently, golden tides have received considerable attention in Korea due to their detrimental effects on the local economy and coastal ecosystems.

Most relevant studies have focused on the transportation, formation, and distribution of golden tides and on the genetic origins and diversity of floating populations [5,11-15]. Several studies have examined the attachment strength, life history traits, photosynthetic activity, and reproduction of S. horneri [16-19]. The extent of golden tides formed by thalli detached from rocky coastal shores of the East China Sea is affected by the density of benthic $S$. horneri populations along the Chinese coast [20]. The duration of the floating period depends on the reproductive state of thalli when they detach from the substratum [21]. Demographic parameters are clearly relevant to the development of golden tides, but few studies have focused on recruitment, biomass, growth, density, and mortality on rocky shores of the northwestern Pacific $[18,21]$. The dearth of population dynamics data for attached S. horneri thalli has prevented predictive modeling of golden tide formation.

Sargassum horneri (Turner) C. Agardh, which is widely distributed along northwestern Pacific coastlines, is a native brown seaweed species with an annual life cycle [22]. This species functions as an ecosystem engineer; it provides habitat, spawning sites, and nursery grounds for a diverse assemblage of marine organisms in coastal ecosystems [23,24]. S. horneri was first introduced to Long Beach Harbor, California, in 2003 [25]. More recently, it has spread aggressively throughout southern California, the USA, and into Baja California, Mexico [26]. S. horneri has an important role in the biofiltration of enriched inorganic nutrients in mainland effluent discharges. The large biomasses that develop during the growing season help maintain and improve water quality [16]. This species has been considered a particularly suitable candidate for reforestation of kelp zones in East Asia, and it has been transplanted to natural and artificial reefs at kelp deforestation sites $[24,27,28]$.

Our study aimed to investigate the population dynamics of $S$. horneri on the southern coast of Korea in order to improve understanding of the magnitude and formation of golden tides. We postulated that (i) the population dynamics of $S$. horneri are affected by local habitat conditions, and (ii) the size of the drifting biomass of $S$. horneri is strongly associated with detachment of $S$. horneri populations. To test these postulates, we examined the morphology, density, recruitment, mortality, growth rate, and biomass of natural S. horneri populations in exposed and semi-sheltered sites on the southern coast of Korea. Data were collected monthly by Scuba diving from November 2017 to October 2018. 
This study should provide valuable information for a better understanding of the extent and formation of golden tides.

\section{Materials and Methods}

\subsection{Study Area}

This study was conducted at two sites, Jindo $\left(34^{\circ} 22^{\prime} 37^{\prime \prime} \mathrm{N}, 126^{\circ} 18^{\prime} 28^{\prime \prime}\right.$ E) and Munseom $\left(33^{\circ} 13^{\prime} 38^{\prime \prime} \mathrm{N}, 126^{\circ} 34^{\prime} 04^{\prime \prime} \mathrm{E}\right)$, which are on the southwestern coast of Korea (Figure 1). The Jindo site was located in Supumhang Harbor; it is a sheltered area with a substratum comprising boulders and stones overlaid with muddy sand. The macroalgal community was dominated primarily by large brown algae (Sargassum horneri, S. thunbergii, S. fulvellum, and Undaria pinnatifida) and ephemeral green algae (Ulva spp.). In particular, $S$. horneri formed dense assemblages at 4-7 $\mathrm{m}$ water depth. In contrast, the Munseom site, located on Jeju Island, is very exposed to wave action originating in the East China Sea. S. horneri dominated water depths of 5-8 $\mathrm{m}$ at Munseom. Kim et al. provided a detailed description of macroalgal assemblages at Munseom [29]. The tidal cycle on the coast is semi-diurnal, and the system is classified as mesotidal, with a maximum tidal range during spring tides of about $3.0 \mathrm{~m}$ at Jindo and $2.7 \mathrm{~m}$ at Munseom (Tide Tables for the Coast of Korea, National Oceanographic Research Institute of Korea).

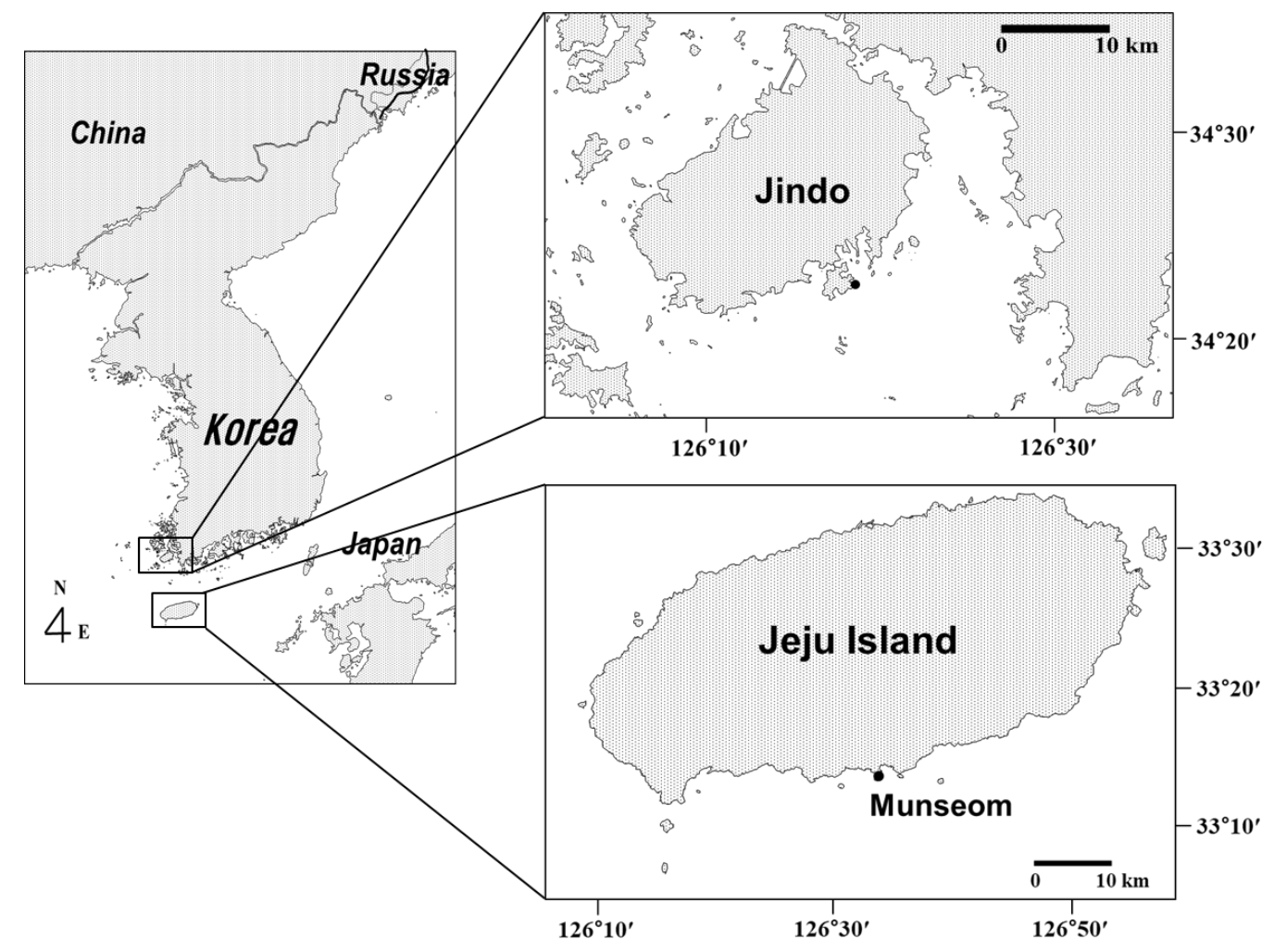

Figure 1. Study sites at Jindo and Munseom, off the southwestern coast of Korea.

\subsection{Sampling Design}

Observations were made monthly at the two sites using Scuba diving in the period from November 2017 to October 2018. In November 2017, we established permanent quadrats at the two sites at water depths in which S. horneri formed dense assemblages. Quadrat sizes were selected according to population densities. Five $1.0 \mathrm{~m}^{2}$ quadrats and four $0.25 \mathrm{~m}^{2}$ quadrats were set at Jindo and Munseom, respectively. Quadrats were spaced at three-meter intervals. All thalli in each quadrat were tagged 
with surveyors' flagging tape and individually numbered for sequential observations on individuals. We marked 100 and 150 thalli at Jindo and Munseom, respectively.

\subsection{Data Collection}

The height, density, mortality, biomass, and growth rates of individuals at each site were recorded monthly in the field from November 2017 to October 2018. Heights were measured as the lengths of the main shoots of undamaged thalli. The main shoot is typically the longest; however, lateral branches may be longer than the main axis when it has been severed by wave action [30]. When this was the case, we used the length of the longest lateral branch as a measure of thallus height. Thallus elongation was calculated using the following formula:

$$
\text { Elongation }\left(\mathrm{cm} \mathrm{day}^{-1}\right)=\left(\mathrm{L}_{\mathrm{t}}-\mathrm{L}_{0}\right) / \mathrm{t},
$$

where $\mathrm{L}_{0}$ is the initial length $(\mathrm{cm})$ of the main shoot axis, $\mathrm{L}_{t}$ is the length $(\mathrm{cm})$ of the main axis after $t$ days, and $t$ is the observation period (days). The growth rates of individuals were calculated using the following equation [31]:

$$
\text { Growth rate of thallus }\left(\% \text { day }^{-1}\right)=\left[\left(L_{t}-L_{0}\right)^{1 / t}-1\right] \times 100 \% \text {. }
$$

The density of thalli was estimated by counting all individuals in the quadrats. The density was converted to units of individuals per $\mathrm{m}^{2}$. Densities (individuals per $\mathrm{m}^{2}$ ) and rates (\%) of monthly mortality were estimated from the number of tagged individuals that disappeared each month. The total biomass of thalli per unit area $\left(\mathrm{m}^{2}\right)$ was estimated by summing the individual predicted weights of thalli in each quadrat. To estimate the individual weights, we collected 60 thalli with a range of main axis lengths monthly from each of the sites to determine the allometric relationship between thallus height $(\mathrm{cm})$ and individual weight ( $\mathrm{g}$ dry weight). The main axis lengths of all undamaged and damaged thalli in each of the quadrats were measured monthly and converted to dry weights using allometric relationship equations. Sargassum horneri usually grows attached to rocks, and it also continues to grow while free-floating. Unfortunately, we were unable to measure elongation in the floating population. Therefore, we assumed that rates of elongation were identical in attached and floating populations. The weights of detached thalli were estimated using the allometric relationship equations. The total detached biomass per unit area $\left(\mathrm{m}^{2}\right)$ was estimated monthly by summing the individual predicted weights of thalli that detached in each quadrat.

We measured water temperature at the two sites every 15 min using HOBO Pendant temperature/light data loggers (Onset Computer Corporation, Bourne, MA, USA). Salinity was measured on each sampling occasion using a YSI salinometer (YSI model 63, YSI incorporated, USA). To determine dissolved inorganic nutrient concentrations $\left(\mathrm{NH}_{4}{ }^{+}, \mathrm{NO}_{3}{ }^{-}, \mathrm{NO}_{2}{ }^{-}\right.$, and $\left.\mathrm{PO}_{4}{ }^{3-}\right)$ in the water column, we collected four replicate surface water samples each month through the experimental period. Water samples were placed on ice in the field and frozen until analyzed. Water column nutrient concentrations were determined using standard colorimetric techniques following the procedures of Parsons et al. [32]. The sum of $\mathrm{NH}_{4}{ }^{+}-\mathrm{N}, \mathrm{NO}_{3}{ }^{-}-\mathrm{N}$, and $\mathrm{NO}_{2}{ }^{-}-\mathrm{N}$ concentrations was recorded as total dissolved inorganic $\mathrm{N}$ (DIN). $\mathrm{PO}_{4}{ }^{3-}$ concentrations were used as a measure of total dissolved inorganic phosphate (DIP).

\subsection{Statistical Analyses}

Significant differences in height, density, elongation, growth rate, biomass, detached biomass, mortality, mortality rate of thalli, and water column nutrients (DIN and DIP) among sampling times and between sites were identified by two-way ANOVA. A two-way ANOVA without replication was performed to test for significant differences in daily mean water temperature between the two study sites. Data were tested for normality and homogeneity of variance prior to analysis to determine whether they met the assumptions of parametric statistics. If these assumptions were not satisfied, data were 
square root transformed (height, density, biomass, detached biomass, mortality, and elongation) or arcsine transformed (mortality rate and growth rate). When significant differences were detected by ANOVA, we performed Student-Newman-Keuls (SNK) post hoc tests to identify significant pairwise differences between means. An alpha level of 0.05 was used for statistical tests. All statistical analyses were performed using IBM SPSS Statistics ver. 20.0 software (IBM Corporation, Armonk, NY, USA).

\section{Results}

\subsection{Environmental Factors}

Water temperature at both sites had distinct seasonal patterns, ranging from $4.6^{\circ} \mathrm{C}$ and $14.6{ }^{\circ} \mathrm{C}$ in February 2017 to $27.3^{\circ} \mathrm{C}$ and $28.4^{\circ} \mathrm{C}$ in August 2018 at Jindo and Munseom, respectively (Figure 2A). Water temperature was significantly higher $(p<0.001)$ at Munseom than at Jindo. While water temperatures during fall, winter, and spring were higher at Munseom than at Jindo, there was no difference in water temperature between the two sites during late spring-summer. Notably, water temperatures during the late August-early September period decreased temporarily at Munseom following the passage of typhoon Soulik. Salinity was relatively constant throughout the study period, with averages of 31.9 and 30 Practical Salinity Unit (PSU) at Jindo and Munseom, respectively (Figure 2B).

Water column DIN concentrations at both study sites varied significantly $(p<0.001)$ with sampling time (Figure 2C). The DIN concentrations at Jindo were significantly higher $(p<0.001)$ than those at Munseom. The average DIN concentrations at Jindo and Munseom were 8.8 and $1.8 \mu \mathrm{M}$, respectively. Water column DIP concentrations at both sites were usually less than $1.0 \mu \mathrm{M}$ during the study period (Figure 2D).
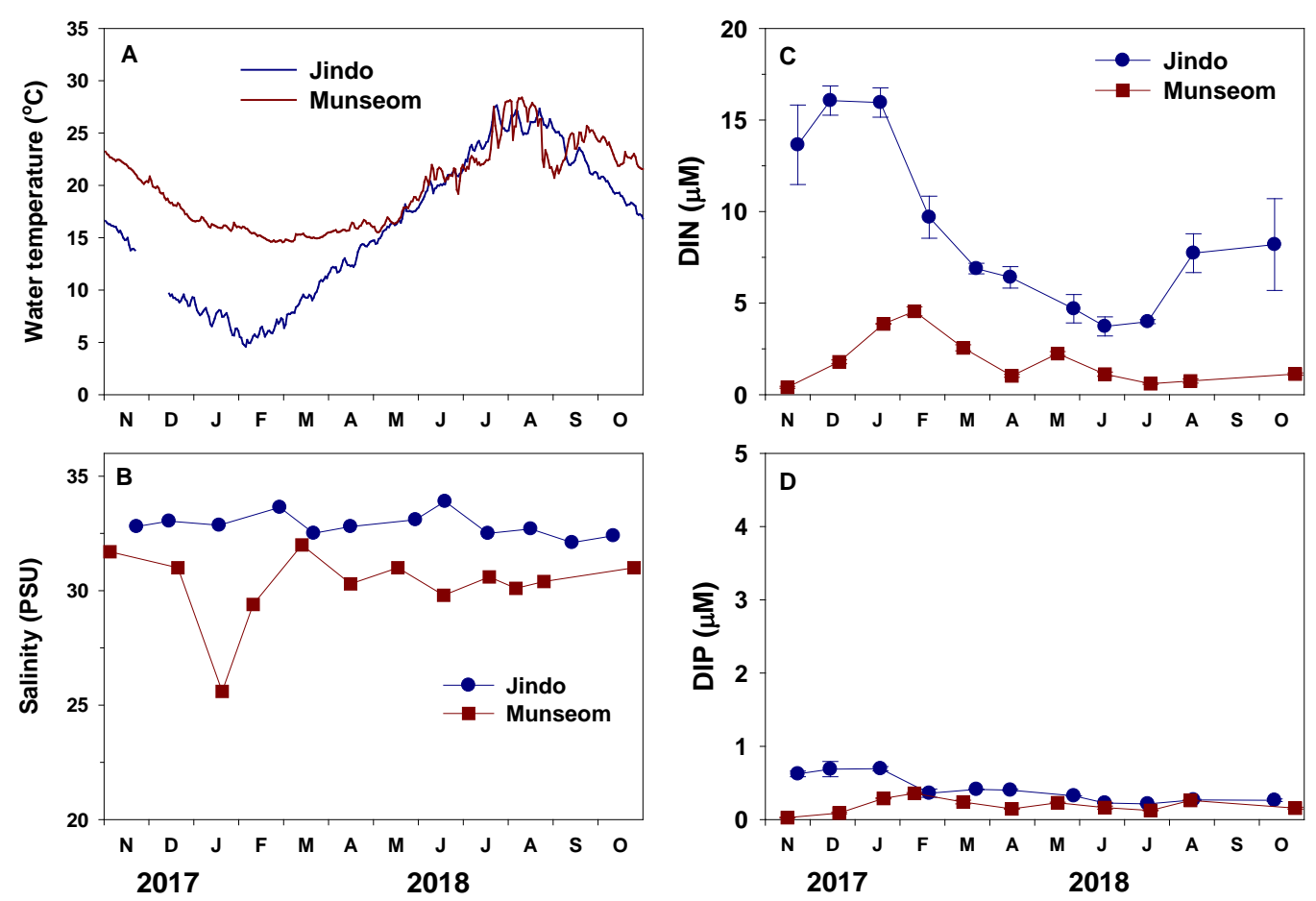

Figure 2. Seasonal variations in water temperature (A), salinity (B), water column dissolved inorganic nitrogen (DIN) (C), and dissolved inorganic phosphate (DIP) (D) concentrations at Jindo and Munseom on the southwestern coast of Korea. The values of DIN and DIP are mean \pm SE $(n=4)$.

\subsection{Density and Mortality}

Sargassum horneri had a clear annual density cycle. Recruitment occurred in the fall (Figure 3A). Thallus density at Munseom was significantly higher $(p<0.001)$ than that at Jindo (Table 1$)$. The species 
had the highest densities during late fall and early winter (November/December), 1-3 months after recruitment; thereafter, densities decreased. All S. horneri thalli had completely disappeared by July. The patterns of mortality density (i.e., thallus losses per unit area) and mortality rate differed markedly between the two sites (Figure 3B,C). The mortality density at Munseom was significantly higher $(p<0.001)$ than that at Jindo due the differences in density between the two sites (Table 1$)$. The mortality rate at Munseom fluctuated greatly with time; it was highest during the periods December-January, March-April, and June-July. The mortality rate of the Jindo population gradually increased over time, with the highest values in April and the period June-July.
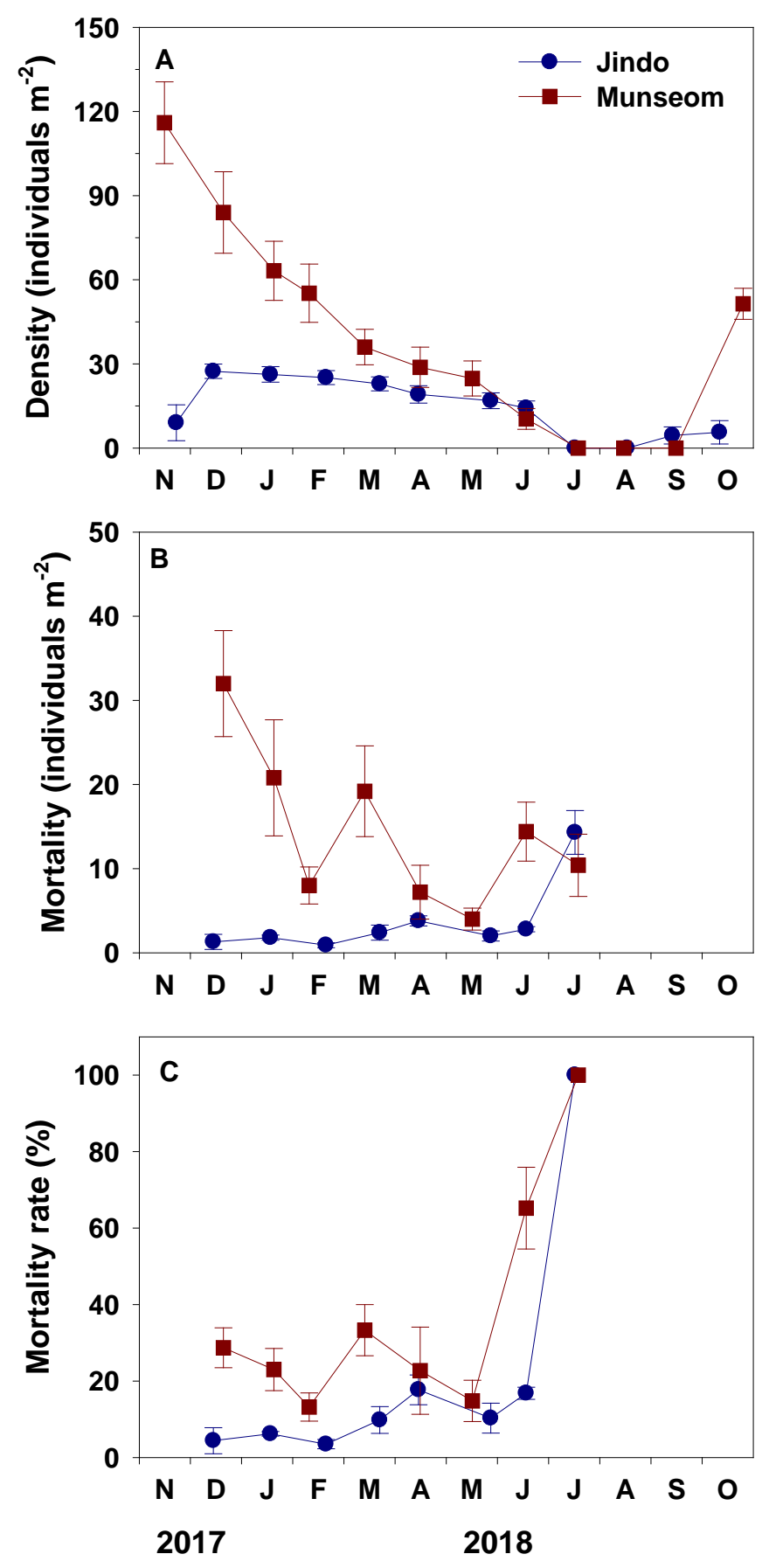

Figure 3. Seasonal variations in total density (A), individuals lost per unit area (mortality density) (B), and mortality rate $(\mathbf{C})$ of Sargassum horneri thalli at Jindo and Munseom. Values are mean \pm SE $(n=4-5)$. 
Table 1. Summary ANOVA tables for height, density, elongation, growth rate, biomass, detached biomass, individuals lost per unit area (mortality density), and mortality rate of Sargassum horneri at Jindo and Munseom. All data were either square root transformed (density, mortality density, height, elongation, biomass, and detached biomass) or arcsine transformed (mortality rate and growth rate) prior to analysis to meet the assumptions of parametric statistics. DF, degrees of freedom; mortality density, individuals lost per unit area.

\begin{tabular}{llcccc}
\hline \multicolumn{1}{c}{ Parameter } & \multicolumn{1}{c}{ Source } & DF & MS & F-ratio & $p$-value \\
\hline \multirow{3}{*}{ Density } & Site & 1 & 96.660 & 70.664 & $<0.001$ \\
& Time & 11 & 58.254 & 42.587 & $<0.001$ \\
& Site $\times$ Time & 11 & 18.271 & 13.357 & $<0.001$ \\
\hline \multirow{3}{*}{ Mortality density } & Site & 1 & 59.968 & 53.806 & $<0.001$ \\
& Time & 7 & 4.347 & 3.901 & $=0.002$ \\
& Site $\times$ Time & 7 & 6.295 & 5.648 & $<0.001$ \\
\hline \multirow{3}{*}{ Mortality rate } & Site & 1 & 0.614 & 23.220 & $<0.001$ \\
& Time & 7 & 2.020 & 76.386 & $<0.001$ \\
& Site $\times$ Time & 7 & 0.090 & 3.401 & $=0.004$ \\
\hline \multirow{3}{*}{ Height } & Site & 1 & 1670.037 & 151.698 & $<0.001$ \\
& Time & 6 & 1885.748 & 171.292 & $<0.001$ \\
& Site $\times$ Time & 6 & 888.421 & 80.700 & $<0.001$ \\
\hline \multirow{3}{*}{ Elongation } & Site & 1 & 110.785 & 294.097 & $<0.001$ \\
& Time & 4 & 12.143 & 32.236 & $<0.001$ \\
& Site $\times$ Time & 4 & 11.902 & 31.595 & $<0.001$ \\
\hline \multirow{2}{*}{ Growth rate } & Site & 1 & 0.380 & 192.995 & $<0.001$ \\
& Time & 4 & 0.059 & 30.065 & $<0.001$ \\
& Site $\times$ Time & 4 & 0.039 & 19.674 & $<0.001$ \\
\hline \multirow{3}{*}{ Diomass } & Site & 1 & 1253.824 & 17.002 & $<0.001$ \\
& Time & 11 & 2441.508 & 33.106 & $<0.001$ \\
& Site $\times$ Time & 11 & 258.725 & 3.508 & $<0.001$ \\
\hline \multirow{2}{*}{ Setached biom } & Site & 1 & 3032.415 & 67.151 & $<0.001$ \\
& Time & 11 & 924.001 & 20.462 & $<0.001$ \\
& Site $\times$ Time & 11 & 393.697 & 8.718 & $<0.001$ \\
\hline
\end{tabular}

\subsection{Height, Growth and Biomass}

The seasonal fluctuations in thallus height differed greatly between sites (Figure 4A). Thallus height at Munseom dramatically increased from November to April, when thalli reached a maximum length $(857 \mathrm{~cm})$. The heights at Jindo gradually increased over the study period, reaching a maximum of $137 \mathrm{~cm}$ in April. After May, the apices of all thalli were damaged or severed by wave action. Elongation varied significantly $(p<0.001)$ between sites (Figure 4B; Table 1$)$. During the growth period, the elongation rate at Munseom was significantly higher $(p<0.001)$ than that at Jindo (Table 1 ). The highest elongation rate, $12.7 \mathrm{~cm} \mathrm{day}^{-1}$, occurred during February at Munseom. The elongation rate was very low at Jindo ( $<0.5 \mathrm{~cm}$ per day). The growth rate was also significantly higher $(p<0.001)$ at Munseom than at Jindo. The highest rate at Jindo occurred in January, and the lowest rate during the period March-April (Figure 4C; Table 1).

Thallus biomass also varied significantly $(p<0.001)$ by season, and patterns differed between sites $(p<0.001)$ (Figure 5A; Table 1$)$. The biomass of the Munseom population increased during fall and winter and decreased during spring and early summer. The biomass of the Jindo population also increased during fall and early winter (September-December), was almost constant from December to April, and decreased between mid-spring and summer (April-July). The maximum population biomasses at Jindo and Munseom were 925 and $3100 \mathrm{~g}$ fresh weight $\mathrm{m}^{-2}$, respectively. The biomass of detached thalli at Munseom varied significantly $(p<0.001)$ with sampling time but did not track a clear seasonal trend (Figure 5B; Table 1). The detached biomass of the Jindo population increased 
gradually through the study period (Figure 5B). The biomass of detached thalli was highest during January and March (average: $1600 \mathrm{~g}$ fresh weight $\mathrm{m}^{-2}$ ) at Munseom and lowest during April and July (average: $250 \mathrm{~g}$ fresh weight $\mathrm{m}^{-2}$ ) at Jindo.
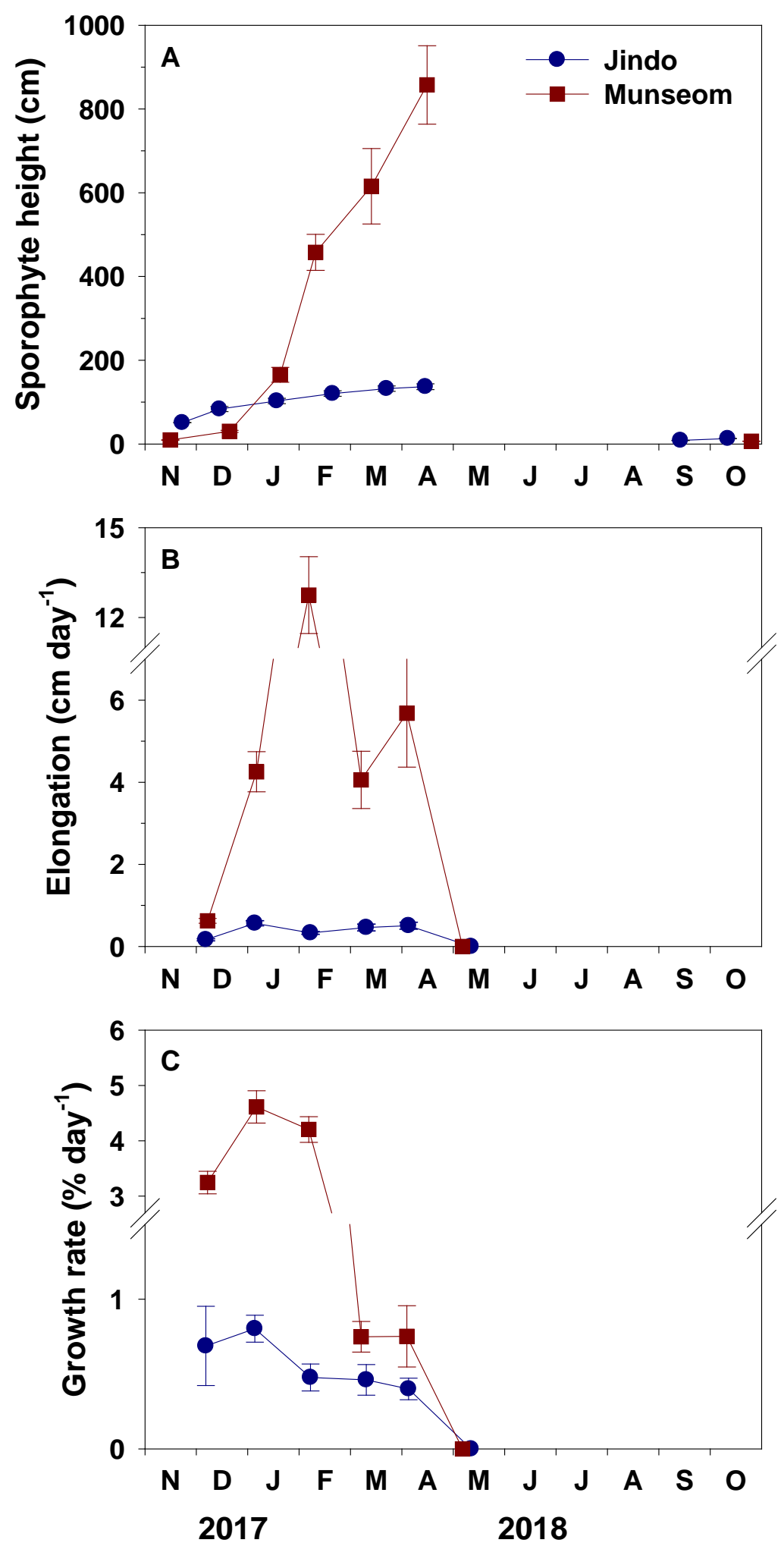

Figure 4. Seasonal changes in height (A), elongation (B), and growth rate (C) of Sargassum horneri thalli at Jindo and Munseom. Values are means \pm SE $(n=10-150)$. 

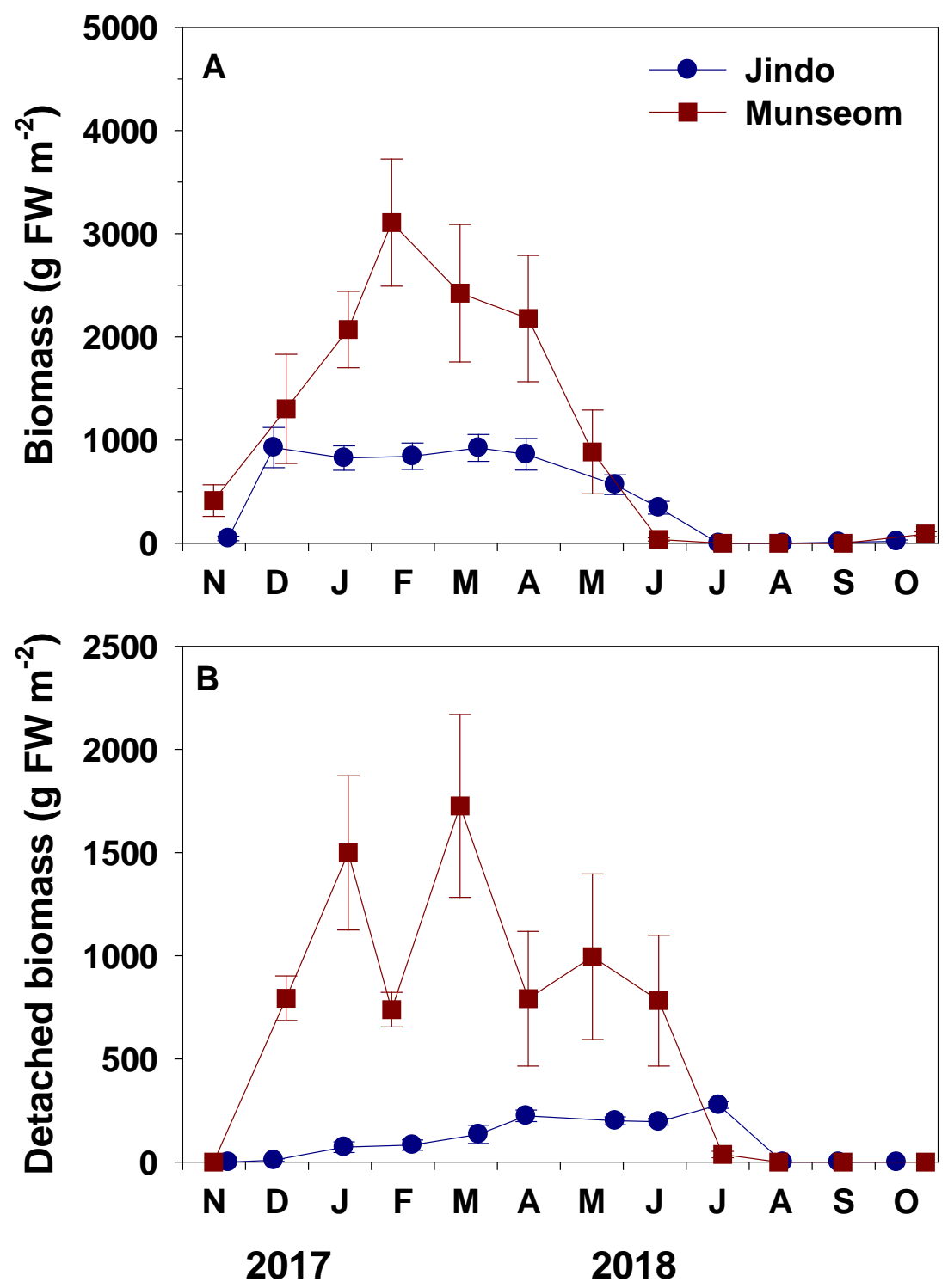

Figure 5. Total biomass (A) and detached biomass (B) of Sargassum horneri thalli at Jindo and Munseom. Values are mean \pm SE $(n=4-5)$. FW, fresh weight.

\subsection{Relationship between Water Temperature and Thallus Biomass}

The biomass of the Jindo population was highest at a water temperature of ca. $5-12{ }^{\circ} \mathrm{C}$ between December and early April; thereafter, it decreased with increasing water temperature (Figure 6A). Elongation peaked at temperatures of about $8-12{ }^{\circ} \mathrm{C}$ in January and during the period March-April, but slowed during May when water temperatures exceeded $16{ }^{\circ} \mathrm{C}$ (Figure $6 \mathrm{C}$ ). Thallus biomass at Munseom was highest at temperatures ca. $14-16{ }^{\circ} \mathrm{C}$ between January and early April, and decreased thereafter with increasing water temperatures (Figure 6B). The peak elongation in the Munseom population occurred at a temperature of about $15{ }^{\circ} \mathrm{C}$ in February, but it fell when temperatures exceeded $16^{\circ} \mathrm{C}$ in May (Figure 6D). 

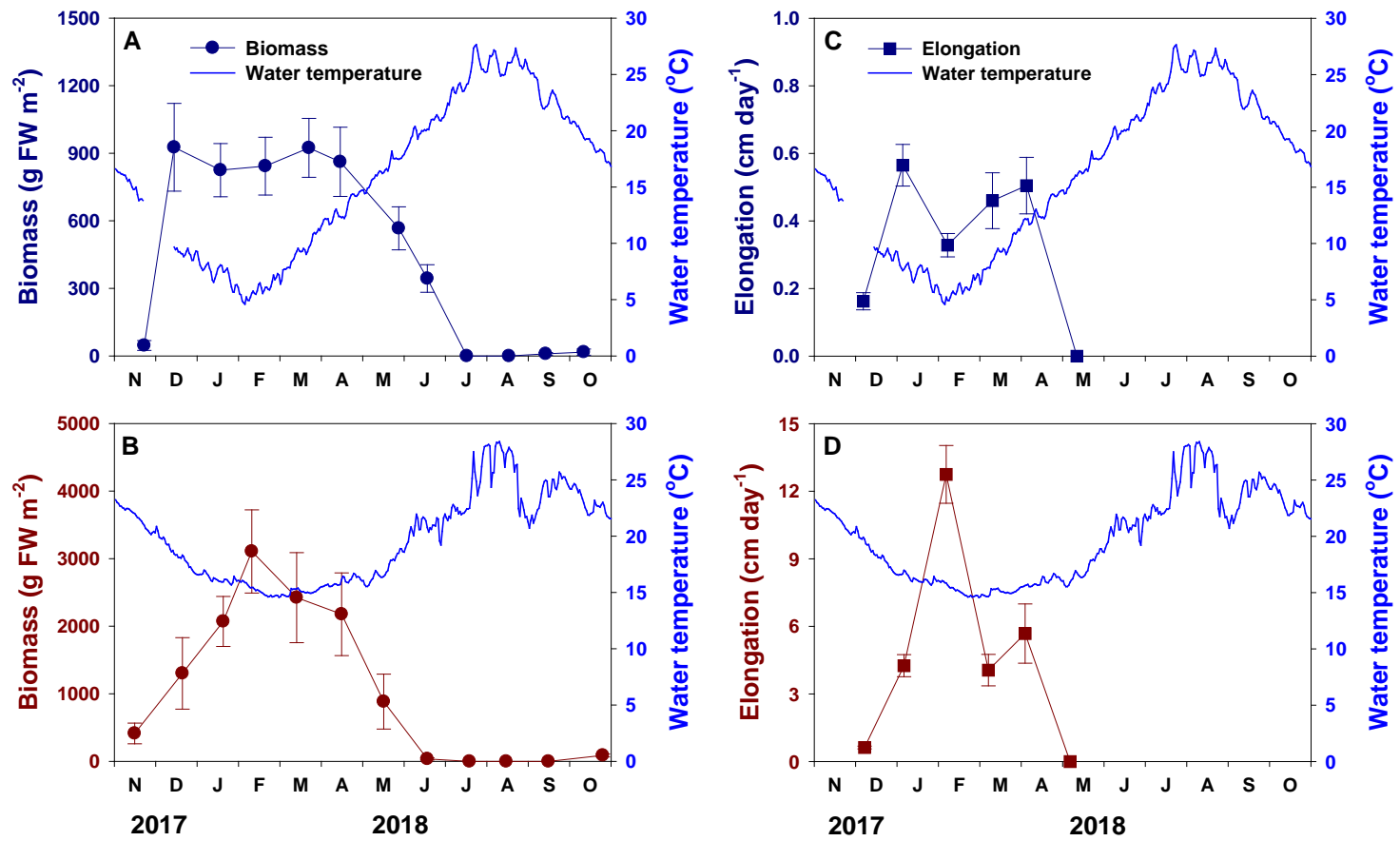

Figure 6. Seasonal trends in water temperature (solid lines) and in biomass (A and $\mathbf{B}$ ) and elongation (C and D) of Sargassum horneri thalli at Jindo (A and C) and Munseom (B and D). The values of biomass $(n=4-5)$ and elongation $(n=10-150)$ are mean \pm SE. FW, fresh weight.

\section{Discussion}

\subsection{Population Dynamics of S. horneri Populations}

The present study showed that two S. horneri populations on the southwestern coast of Korea had obligate annual life cycles. The demographic parameters of both populations exhibited strong seasonal variation: Recruiting during September-November, growing and maturing during November-April, and disappearing during July. These patterns reflected seasonal changes in water temperatures, which have conspicuous impacts on the growth of S. horneri. Seasonal trends in S. horneri populations (increasing during fall and spring and decreasing during spring and early summer) have been reported for the northwest Pacific coasts $[30,33,34]$. Water temperature is a vital driver of seasonal variation in Sargassum spp. biomasses within the seaweed beds at Ningaloo [35]. We found that S. horneri at both study sites had maximum biomass and elongation at temperatures in the range $5-15{ }^{\circ} \mathrm{C}$ during winter and spring, although two sites had different seasonal trends in water temperature. This finding was similar to those of previous studies on persistent $S$. horneri beds along the coast of Japan; the optimal temperature for $S$. horneri growth in Japan ranged between 10 and $15{ }^{\circ} \mathrm{C}[30,33,36]$. In our study, the growth rate of the two populations was highest at water temperatures within the $5-15^{\circ} \mathrm{C}$ range during the winter-spring period, similar to the findings of Yu et al., who showed that the specific growth rates for length and weight in $S$. horneri increased when water temperature rose from $5{ }^{\circ} \mathrm{C}$ to $20^{\circ} \mathrm{C}$ [37]. Thus, we showed that water temperature can be considered a major factor controlling the growth and maturation of Sargassum spp. [33,38].

The two populations we studied exhibited obviously different trends in height, density, biomass, and mortality. The height, density, biomass, elongation, and growth rate at Munseom were 5-10 times higher than those at Jindo. Nutrient availability influences the growth, productivity, and community structure of seaweeds $[39,40]$. The growth patterns of kelp species are strongly affected by local nutrient availability [41]. Nitrogen enrichment enhances the specific growth rates of length and weight in S. horneri and promotes high biomass accumulation of drifting thalli [37]. The water column DIN and DIP concentrations at Jindo were significantly higher than those at Munseom. It is likely that 
the ambient nutrient level at Jindo provided adequate nutrients for $S$. horneri growth. Nevertheless, the Jindo population had lower height, density, biomass, elongation, and growth rate than the Jeju population. Therefore, the difference in growth between the two populations cannot be attributed to differences in nutrient availability.

The variability in the growth rate and morphology of $S$. horneri has been linked to water temperature [36]. Warming promotes higher Sargassum growth rates by increasing rates of metabolism and photosynthetic activity before the thalli decay [42]. During winter, S. horneri thalli exposed to high water temperatures have increased growth rates and lengths, and earlier maturation than those in cooler waters [30]. The average water temperature at Munseom $\left(16.2^{\circ} \mathrm{C}\right)$ was higher than at Jindo $\left(8.9^{\circ} \mathrm{C}\right)$ during the growing season (December-April). After January, the Munseom thalli grew more rapidly and reached larger sizes than the Jindo thalli. Thalli with receptacles were found in Munseom during early March; receptacles were first observed on Jindo thalli in mid-April (S.R. Park, personal observation).

Wave action is also considered an important factor in the growth of large brown algae when there are minimal differences in other environmental factors between sites, such as light, temperature, and nutrients [43]. Wave action has an impact on the growth and productivity of macroalgae [44,45]. The morphology and survival of seaweeds is related to water flows created by waves or currents $[18,46]$. Thus, wave activity or wave-induced water motion is considered an important controlling factor in algal community structure and composition $[47,48]$. Munseom is located on the southern coast of Jeju Island, where it is directly open to the East China Sea. Thus, the Munseom population was likely exposed to higher wave activity than the Jindo population. The degree of exposure to wave action may account for the large differences in morphology, density, biomass, and mortality that we observed between the two populations. Therefore, wave exposure and warmer water temperatures during the winter season were probably key drivers of S. horneri growth.

\subsection{Contribution of Mortality to the Formation of Golden Tides}

Since the early years of the current century, massive drifting mats of $S$. horneri have been frequently observed along the East China Sea coast. They have aggressively spread along the length of the southwestern coast of Korea (including Jeju Island) and the western coast of Japan [11,49-51]. Floating S. horneri rafts originated from attached thalli in the subtidal zones of islands off Zhejiang Province, China, and were transported northeastwards with oceanic currents and wind $[5,11,13,14]$. The floating S. horneri biomass therefore depends on the biomass of the attached source populations. The biomass of attached benthic populations of S. horneri off Gouqi Island, China, where the massive drifting S. horneri rafts in the East China Sea originated, ranged from $0.54 \mathrm{~kg}$ fresh weight $\mathrm{m}^{-2}$ in August to $4.42 \mathrm{~kg}$ fresh weight $\mathrm{m}^{-2}$ in June [52]. The maximum biomass of attached S. horneri in Obama Bay, Japan, averaged $555 \mathrm{~g}$ dry weight $\mathrm{m}^{-2}$ (ca. $2.8 \mathrm{~kg}$ fresh weight $\mathrm{m}^{-2}$, using a dry weight: fresh weight ratio of 0.2) [33]. In contrast, non-native populations of S. horneri in Todos Santos Bay, Mexico, had very low biomass, ranging from $3 \mathrm{~g}$ dry weight $\mathrm{m}^{-2}$ (ca. $15 \mathrm{~g}$ fresh weight $\mathrm{m}^{-2}$ ) to $78 \mathrm{~g}$ dry weight $\mathrm{m}^{-2}$ (ca. $390 \mathrm{~g}$ fresh weight $\mathrm{m}^{-2}$ ) [53]. S. horneri biomass at Munseom and Jindo ranged from $0.6 \mathrm{~kg}$ fresh weight $\mathrm{m}^{-2}$ to $3.1 \mathrm{~kg}$ fresh weight $\mathrm{m}^{-2}$ during the growing season (December-May); this range was similar to those measured in S. horneri populations in China and Japan [33,52]. The maximum biomasses of S. horneri fragments detached from attached thalli at Munseom were $1.5 \pm 0.4$ and $1.7 \pm 0.5 \mathrm{~kg}$ fresh weight $\mathrm{m}^{-2}$ in January and March, respectively, when mortality was high. The floating $S$. horneri biomass in the East China Sea was ca. $2 \mathrm{~kg}$ fresh weight $\mathrm{m}^{-2}$. The estimated floating biomass of Sargassum in the Florida straits and the Gulf of Mexico ranged from $1.26 \mathrm{~kg}$ fresh weight $\mathrm{m}^{-2}$ to $6.74 \mathrm{~kg}$ fresh weight $\mathrm{m}^{-2}$, averaging $3.34 \mathrm{~kg}$ fresh weight $\mathrm{m}^{-2}[10,20]$. Given that detached $S$. horneri thalli continue to grow during the floating period [21], our estimates of floating biomass are similar to those reported for the East China Sea, the Florida Straits, and the Gulf of Mexico [10,20]. Our results provide a quantitative assessment of the overall floating Sargassum biomass. 
Similar to those around the islands off Zhejiang Province, the S. horneri population at Munseom was exposed to high wave action and had high mortality rates and densities during the December-January period and March, suggesting that large drifting seaweed rafts may be produced by detaching thalli. When high mortality occurs around the islands off Zhejiang Province and floating $S$. horneri mats form in the Yellow Sea and East China Sea, drifting S. horneri rafts can be observed in the southern part of Jeju Island, Korea, within approximately a month [51]. Large mats of drifing S. horneri were introduced to the Korean coasts by the Kuroshio Current and Taiwan Warm Current in the late January-February and April-early May periods of 2015-2019. These rafts accumulated along the southern coast of Korea, including Jeju Island [14,54]. High mortality rates and/or densities likely also occurred among the islands off Zhejiang Province during the December-January period and March. If so, this would strongly support our second postulate, namely that the biomass of drifting $S$. horneri is strongly associated with mortality in attached S. horneri populations. Unfortunately, there are few data for the S. horneri populations among the islands off Zhejiang Province, China, which severely limits more detailed interpretation of the extent and formation of golden tides in the East China Sea. Therefore, further studies of the populations among the islands off Zhejiang Province are required to better understand the extent and formation processes of drifting S. horneri mats.

\section{Conclusions}

Recently, massive S. horneri mats have resulted in devastating impacts on the local economy and coastal ecosystems in Korea. A dangerous combination of wave and tide conditions can exacerbate economic losses due to Sargassum beaching events. Thus, predicting the timing and extent of golden tides will provide early-warning of Sargassum beaching. The results of this study confirm that S. horneri had a clear annual life cycle and exhibited seasonal variations in density, which reflected seasonal changes in water temperature. Furthermore, the difference in height, density, growth, and mortality between the two sites may be affected by the degree of exposure to wave action. High mortality density at the study site was observed during the December-January period and in March. The detached thalli had an effect on the extent and formation of floating S. horneri mats. This result showed that the biomass of S. horneri thalli detached from substrata was approximately $1.6 \mathrm{~kg}$ fresh weight $\mathrm{m}^{-2}$ during high mortality periods. This will help us to estimate the extent and formation timing of golden tides. However, most seaweeds show inter-annual variation in their biomass, and environmental conditions were temporally not constant. Thus, long-term monitoring, with more study sites, is needed to fully predict the extent and formation timing of drifting $S$. horneri mats.

Author Contributions: Conceptualization, S.K.C., S.K., and S.R.P.; methodology, S.K.C., H.-J.O., S.-H.Y., S.K., and S.R.P.; formal Analysis, H.J.L., K.L., Y.S.H., and S.R.P.; investigation, S.K.C., H.-J.O., S.-H.Y., S.K., and S.R.P.; writing-original draft preparation, S.K.C., S.K., and S.R.P.; writing-review and editing, S.K.C., S.K., and S.R.P. All authors have read and agreed to the published version of the manuscript.

Funding: This research was a part of the project titled 'Development of the collecting treatment system and resources technology for Sagrassum horneri' funded by the Ministry of Oceans and Fisheries, Korea. This work was also supported by a grant from the National Institute of Fisheries Science (R2020045).

Acknowledgments: We would like to thank K.L. Moon, B.S. Song, and T.H. Kim for field assistance and laboratory support.

Conflicts of Interest: The authors declare no conflict of interest.

\section{References}

1. Smetacek, V.; Zingone, A. Green and golden seaweed tides on the rise. Nature 2013, 504, 84-88. [CrossRef]

2. Wang, M.; Hu, C.; Barnes, B.B.; Mitchum, G.; Lapointe, B.; Montoya, J.P. The great Atlantic Sargassum belt. Science 2019, 365, 83-87. [CrossRef]

3. Lapointe, B.E. A comparison of nutrient-limited productivity in Sargassum natans from neritic vs. oceanic waters of the western North Atlantic Ocean. Limnol. Oceanogr. 1995, 40, 625-633. [CrossRef] 
4. Fletcher, R.L. The occurrence of "green tides"-A review. In Marine Benthic Vegetation; Springer: Berlin, Germany, 1996; pp. 7-43.

5. Qi, L.; Hu, C.; Wang, M.; Shang, S.; Wilson, C. Floating algae blooms in the East China Sea. Geophys. Res. Lett. 2017, 44, 11501-11509. [CrossRef]

6. Cho, S.-H.; Myoung, J.-G.; Kim, J.-M.; Lee, J.H. Fish fauna associated with drifting seaweed in the coastal area of Tongyeong, Korea. Trans. Am. Fish. Soc. 2001, 130, 1190-1202. [CrossRef]

7. Thiel, M.; Gutow, L. The ecology of rafting in the marine environment. I. The floating substrata. In Oceanography and Marine Biology: An Annual Review; Gibson, R.N., Atkinson, R.J.A., Gordon, J.D.M., Eds.; CRC Press: Boca Raton, FL, USA, 2005; Volume 42, pp. 181-264.

8. Witherington, B.; Hirama, S.; Hardy, R. Young sea turtles of the pelagic Sargassum-dominated drift community: Habitat use, population density, and threats. Mar. Ecol. Prog. Ser. 2012, 463, 1-22. [CrossRef]

9. Ha, D.S.; Yoo, H.I.; Chang, S.J.; Hwang, E.K. Bloom of a filamentous green alga Cladophora vadorum (Areschoug) Kützing and nutrient levels at Shangrok beach, Buan, Korea. Korean J. Fish. Aquat. Sci. 2016, 49, 241-246.

10. Wang, M.; Hu, C.; Cannizzaro, J.; English, D.; Han, X.; Naar, D.; Lapointe, B.; Brewton, R.; Hernandez, F. Remote sensing of Sargassum biomass, nutrients, and pigments. Geophys. Res. Lett. 2018, 45, 12359-12367. [CrossRef]

11. Komatsu, T.; Tatsukawa, K.; Filippi, J.B.; Sagawa, T.; Matsunaga, D.; Mikami, A.; Ishida, K.; Ajisaka, T.; Tanaka, K.; Aoki, M. Distribution of drifting seaweeds in eastern East China Sea. J. Mar. Syst. 2007, 67, 245-252. [CrossRef]

12. Zhang, J.; Ding, X.; Zhuang, M.; Wang, S.; Chen, L.; Shen, H.; He, P. An increase in new Sargassum (Phaeophyceae) blooms along the coast of the East China Sea and Yellow Sea. Phycologia 2019, 58, 374-381. [CrossRef]

13. Liu, F.; Liu, X.; Wang, Y.; Jin, Z.; Moejes, F.W.; Sun, S. Insights on the Sargassum horneri golden tides in the Yellow Sea inferred from morphological and molecular data. Limnol. Oceanogr. 2018, 63, 1762-1773. [CrossRef]

14. Byeon, S.Y.; Oh, H.-J.; Kim, S.; Yun, S.H.; Kang, J.H.; Park, S.R.; Lee, H.J. The origin and population genetic structure of the 'golden tide'seaweeds, Sargassum horneri, in Korean waters. Sci. Rep. 2019, 9, 1-13. [CrossRef] [PubMed]

15. Hu, Z.M.; Uwai, S.; Yu, S.H.; Komatsu, T.; Ajisaka, T.; Duan, D.L. Phylogeographic heterogeneity of the brown macroalga Sargassum horneri (Fucaceae) in the northwestern Pacific in relation to late Pleistocene glaciation and tectonic configurations. Mol. Ecol. 2011, 20, 3894-3909. [CrossRef] [PubMed]

16. Pang, S.J.; Liu, F.; Shan, T.F.; Gao, S.Q.; Zhang, Z.H. Cultivation of the brown alga Sargassum horneri: Sexual reproduction and seedling production in tank culture under reduced solar irradiance in ambient temperature. J. Appl. Phycol. 2009, 21, 413-422. [CrossRef]

17. Xie, X.; Wang, G.; Pan, G.; Sun, J.; Li, J. Development of oogonia of Sargassum horneri (Fucales, Heterokontophyta) and concomitant variations in PSII photosynthetic activities. Phycologia 2014, 53, 10-14. [CrossRef]

18. $\mathrm{Xu}, \mathrm{M}$.; Sakamoto, S.; Komatsu, T. Attachment strength of the subtidal seaweed Sargassum horneri (Turner) C. Agardh varies among development stages and depths. J. Appl. Phycol. 2016, 28, 3679-3687. [CrossRef]

19. Marks, L.M.; Reed, D.C.; Holbrook, S.J. Life history traits of the invasive seaweed Sargassum horneri at Santa Catalina Island, California. Aquat. Invasions 2018, 13, 339-350. [CrossRef]

20. Mizuno, S.; Ajisaka, T.; Lahbib, S.; Kokubu, Y.; Alabsi, M.; Komatsu, T. Spatial distributions of floating seaweeds in the East China Sea from late winter to early spring. J. Appl. Phycol. 2014, 26, 1159-1167. [CrossRef]

21. Yatsuya, K. Floating period of Sargassacean thalli estimated by the change in density. J. Appl. Phycol. 2008, 20, 797-800. [CrossRef]

22. Yoshida, G.; Arima, S.; Terawaki, T. Growth and maturation of the 'autumn-fruiting type' of Sargassum horneri (Fucales, Phaeophyta) and comparisons with the 'spring-fruiting type'. Phycol. Res. 1998, 46, 183-189. [CrossRef]

23. Komatsu, T.; Ariyama, H.; Nakahara, H.; Sakamoto, W. Spatial and temporal distributions of water temperature in a Sargassum forest. J. Oceanogr. Soc. Jpn. 1982, 38, 63-72. [CrossRef]

24. Choi, C.G.; Kim, H.G.; Sohn, C.H. Transplantation of young fronds of Sargassum horneri for construction of seaweed beds. Korean J. Fish. Aquat. Sci. 2003, 36, 469-473. 
25. Miller, K.A.; Engle, J.M.; Uwai, S.; Kawai, H. First report of the Asian seaweed Sargassum filicinum Harvey (Fucales) in California, USA. Biol. Invasions 2007, 9, 609. [CrossRef]

26. Marks, L.M.; Salinas-Ruiz, P.; Reed, D.C.; Holbrook, S.J.; Culver, C.S.; Engle, J.M.; Kushner, D.J.; Caselle, J.E.; Freiwald, J.; Williams, J.P. Range expansion of a non-native, invasive macroalga Sargassum horneri (Turner) C. Agardh, 1820 in the eastern Pacific. Bioinvasions Rec. 2015, 4, 243-248. [CrossRef]

27. Yamauchi, K. The formation of Sargassum beds on artificial substrata by Transplanting Seedlings of S. horneri (Turner) C. Agardh and S. muticum (Yendo) Fensholt. Bull. Jpn. Soc. Sci. Fish. 1984, 50, 1115-1123. [CrossRef]

28. Zhang, S.Y.; Bi, Y.X.; Wu, Z.L. Spatial distribution pattern of Sargassum horneri around Gouqi Island, Shengsi, China. J. Fish. China 2013, 37, 884-893. [CrossRef]

29. Kim, S.; Kang, Y.H.; Kim, T.-H.; Lee, H.J.; Park, S.R. Use of morphological characteristics for calculating individual biomass in the kelp Ecklonia cava. J. Appl. Phycol. 2017, 29, 2587-2593. [CrossRef]

30. Mikami, A.; Komatsu, T.; Aoki, M.; Yokohama, Y. Seasonal changes in growth and photosynthesis-light curves of Sargassum horneri (Fucales, Phaeophyta) in Oura Bay on the coast of central Honshu, Japan. La mer 2006, 44, 109-118.

31. Yong, Y.S.; Yong, W.T.L.; Anton, A. Analysis of formulae for determination of seaweed growth rate. J. Appl. Phycol. 2013, 25, 1831-1834. [CrossRef]

32. Parsons, T.R.; Maita, Y.; Lalli, C.M. A Manual of Chemical and Biological Methods for Seawater Analysis; Pergamon Press: Oxford, UK, 1984; p. 173.

33. Umezaki, I. Ecological studies of Sargassum horneri (Turner) C. Agardh in Obama Bay, Japan Sea. Bull. Jpn. Soc. Sci. Fish. 1984, 50, 1193-1200. [CrossRef]

34. Murakami, K.; Yamaguchi, Y.; Sugawa-Katayama, Y.; Katayama, M. Effect of water depth on seasonal variation in the chemical composition of Akamoku, Sargassum horneri (Turner) C. Agardh. Nat. Resour. 2016, 7, 147-156.

35. Fulton, C.J.; Depczynski, M.; Holmes, T.H.; Noble, M.M.; Radford, B.; Wernberg, T.; Wilson, S.K. Sea temperature shapes seasonal fluctuations in seaweed biomass within the Ningaloo coral reef ecosystem. Limnol. Oceanogr. 2014, 59, 156-166. [CrossRef]

36. Yoshida, G.; Murase, N.; Arai, S.; Terawaki, T. Ecotypic differentiation in maturation seasonality among Sargassum horneri (Fucales, Phaeophyta) populations in Hiroshima Bay, Seto Inland Sea, Japan. Phycologia 2004, 43, 703-710. [CrossRef]

37. Yu, J.; Li, J.; Wang, Q.; Liu, Y.; Gong, Q. Growth and resource accumulation of drifting Sargassum horneri (fucales, phaeophyta) in response to temperature and nitrogen supply. J. Ocean Univ. China 2019, 18, 1216-1226. [CrossRef]

38. Hales, J.M.; Fletcher, R.L. Studies on the recently introduced brown alga Sargassum muticum (Yendo) Fensholt. V. Receptacle initiation and growth, and gamete release in laboratory culture. Bot. Mar. 1990, 33, 241-250. [CrossRef]

39. Borchardt, M.A. Nutrients. In Algal Ecology: Freshwater Benthic Ecosystems; Stevenson, R.J., Bothwell, M.L., Lowe, R.L., Eds.; Academic Press: San Diego, CA, USA, 1996; pp. 183-227.

40. Larned, S.T. Nitrogen-versus phosphorus-limited growth and sources of nutrients for coral reef macroalgae. Mar. Biol. 1998, 132, 409-421. [CrossRef]

41. Gagné, J.A.; Mann, K.H.; Chapman, A.R.O. Seasonal patterns of growth and storage in Laminaria longicruris in relation to differing patterns of availability of nitrogen in the water. Mar. Biol. 1982, 69, 91-101. [CrossRef]

42. Vuki, V.C.; Price, I.R. Seasonal changes in the Sargassum populations on a fringing coral reef, Magnetic Island, Great Barrier Reef region, Australia. Aquat. Bot. 1994, 48, 153-166. [CrossRef]

43. Kregting, L.; Blight, A.J.; Elsäßer, B.; Savidge, G. The influence of water motion on the growth rate of the kelp Laminaria digitata. J. Exp. Mar. Biol. Ecol. 2016, 478, 86-95. [CrossRef]

44. Yoshida, G.; Yoshikawa, K.; Terawaki, T. Growth and maturation of two populations of Sargassum horneri (Fucales, Phaeophyta) in Hiroshima Bay, the Seto Inland Sea. Fish. Sci. 2001, 67, 1023-1029. [CrossRef]

45. Engelen, A.H.; Åberg, P.; Olsen, J.L.; Stam, W.T.; Breeman, A.M. Effects of wave exposure and depth on biomass, density and fertility of the fucoid seaweed Sargassum polyceratium (Phaeophyta, Sargassaceae). Eur. J. Phycol. 2005, 40, 149-158. [CrossRef]

46. Harder, D.L.; Hurd, C.L.; Speck, T. Comparison of mechanical properties of four large, wave-exposed seaweeds. Am. J. Bot. 2006, 93, 1426-1432. [CrossRef] [PubMed] 
47. Engledow, H.R.; Bolton, J.J. Seaweed $\alpha$-diversity within the lower eulittoral zone in Namibia: The effects of wave action, sand inundation, mussels and limpets. Bot. Mar. 1994, 37, 267-276. [CrossRef]

48. Díez, I.; Santolaria, A.; Gorostiaga, J.M. The relationship of environmental factors to the structure and distribution of subtidal seaweed vegetation of the western Basque coast (N Spain). Estuar. Coast. Shelf Sci. 2003, 56, 1041-1054. [CrossRef]

49. Konishi, Y. Drifting seaweeds coming from China too. Seikai Fish. Res. Instit. News 2000, 103, 11-15.

50. Lin, S.-M.; Huang, R.; Ogawa, H.; Liu, L.-C.; Wang, Y.-C.; Chiou, Y. Assessment of germling ability of the introduced marine brown alga, Sargassum horneri, in Northern Taiwan. J. Appl. Phycol. 2017, 29, 2641-2649. [CrossRef]

51. Kim, K.; Shin, J.; Kim, K.Y.; Ryu, J.-H. Long-Term Trend of Green and Golden Tides in the Eastern Yellow Sea. J. Coast. Res. 2019, 90, 317-323. [CrossRef]

52. Zhang, S.Y.; Wang, L.; Wang, W.D. Algal communities at Gouqi Island in the Zhoushan archipelago, China. J. Appl. Phycol. 2008, 20, 853-861. [CrossRef]

53. Cruz-Trejo, G.I.; Ibarra-Obando, S.E.; Aguilar-Rosas, L.E.; Poumian-Tapia, M.; Solana-Arellano, E. Presence of Sargassum horneri at Todos Santos Bay, Baja California, Mexico: Its effects on the local macroalgae community. Am. J. Plant. Sci. 2015, 6, 2693-2707. [CrossRef]

54. Hwang, E.K.; Lee, S.J.; Ha, D.S.; Park, C.S. Sargassum golden tides in the Shinan-gun and Jeju Island, Korea. Korean J. Fish. Aquat. Sci. 2016, 49, 689-693.

(C) 2020 by the authors. Licensee MDPI, Basel, Switzerland. This article is an open access article distributed under the terms and conditions of the Creative Commons Attribution (CC BY) license (http://creativecommons.org/licenses/by/4.0/). 